\title{
Simulasi parameter geometri regenerator mesin termoakustik
}

\section{Regenerators geometrical parameter simulation of thermoacoustic engine}

\section{N. Nurpatria*, S. Syahrul, P. Pandiatmi, I.M.A. Sayoga, A. Mulyanto}

Jurusan Teknik Mesin, Fakultas Teknik, Universitas Mataram, Jl. Majapahit No. 62, Mataram, NTB, 83125, Indonesia. HP. 082111738971

*E-mail: nurpatria@unram.ac.id

\section{ARTICLE INFO ABSTRACT}

Article History:

Received 23 February 2019

Accepted 16 Maret 2019

Available online 1 July 2019

Keywords:

Biomass

Simulation

DELTA-EC

Thermoacoustic engine

Regenerator

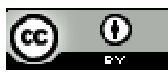

The utilization potentials of biomass energy in Indonesia is very large. As modeled in this paper, the energy carrier flue gas from biomass combustion in the form of heat and temperature is applied as thermodynamic source for the thermoacoustic engine model. Therefore, 33 different models were constructed, modified, and tested in DELTA-EC software simulation in order to reveal their capability. The performance based on the criterion of their acoustic power output and efficiency in a set of various combination of two regenerator geometry parameters applied, radial cross-sectional area and length. The simulation results show that greater the cross-sectional area, greater the acoustic power and engines efficiency. The smallest regenerator size is at 80 $\mathrm{mm}^{2}$ cross-sectional area and $54 \mathrm{~mm}$ length, generates acoustic power of $5.812 \mathrm{~W}$ with its corresponding efficiency of $0.686 \%$. While the biggest regenerator in volume at $120 \mathrm{~mm}^{2}$ and $165 \mathrm{~mm}$ in size, be able to amplified acoustic power up to $22.810 \mathrm{~W}$ with efficiency of $2.693 \%$. An engine model with the highest performance produces acoustic power of $25.848 \mathrm{~W}$ and efficiency of $3.051 \%$. This model uses an optimal regenerators dimension with $120 \mathrm{~mm}^{2}$ area at length of $150 \mathrm{~mm}$.

\section{PENDAHULUAN}

Berdasarkan data BPPT dalam Yudiartono dkk. (2018), potensi energi biomassa yang tersedia di Indonesia sangat besar, setara 32654 MWe. Berdasarkan data tersebut, terbuka kesempatan sangat prospektif bagi implementasi teknologi apapun yang dapat menggunakan energi biomassa sebagai sumber bahan bakarnya. Penggunaan biomassa sebagai bahan bakar mesin pembakaran dalam memerlukan teknologi antara untuk memproses biomassa agar aman serta menjadi bahan bakar berkondisi padat energi termurnikan, atau biasa diistilahkan sebagai high grade energi (HGE). Namun demikian, teknologi proses biomassa menjadi HGE masih terbatas karena kompleksitas peralatan pendukungnya, Siregar dkk. (2017). 
Disisi lain, berkembang teknologi mesin termoakustik yang termasuk mesin pembakaran luar. Secara konstruksi, mesin termoakustik berkomponen sedikit. Tidak seperti mesin pembakaran dalam pada umumnya, mesin termoakustik tidak mempunyai bagian bergerak. Jenis mesin ini dapat didesain agar fleksibel menerima sumber kalor dari berbagai sumber termasuk energi kalor pembakaran biomassa yang belum diproses, yaitu salah satu jenis low grade energy (LGE). Konversi energi kalor menjadi energi akustik dalam mesin termoakustik terjadi dengan perantaraan siklus termodinamika dalam material berpori yang disebut Regenerator (REG). Konversi lebih lanjut energi akustik menjadi energi mekanis dimungkinkan diperoleh dengan mengekstraksi komponen amplitudo tekanan pada gelombang akustik tersebut. Dua diantara karakteristik geometri dari regenerator adalah luas area penampang dan panjang.

Di dalam Thermoacoustic Engine (TAE) atau Mesin Termoakustik diperlukan adanya gradien temperatur dalam arah aliran energi akustik agar regenerator bisa membangkitkan daya akustik. Gradien temperatur tersebut dimungkinkan ada dengan terpasangnya dua komponen lain, yaitu Hot Heat Exchanger (HHX), Penukar Kalor Sisi Panas, dan Cold Heat Exchanger (CHX) atau Penukar Kalor Sisi Dingin. Keduanya ditempatkan di kedua sisi regenerator. Komponen lain adalah saluran penghubung (DUCT) agar mesin membentuk loop. Ada dua jenis mesin termoakustik yang dikenal, tergantung mode gelombang akustik dalam mesin; Standing Wave dan Travelling Wave. Dikarenakan karakteristik travelling-wave, Travelling Wave Thermoacoustic Engine (TATWE) mampu bekerja menurut siklus termodinamika serupa siklus Stirling, yang memberikan efisiensi relatif tinggi. Hal ini menjadi salah satu faktor pertimbangan sehingga di dalam tulisan ini dilakukan simulasi mesin termoakustik jenis TATWE.

Ceperley (1979) dapat memahami bahwa ketika travelling-wave melewati regenerator yang memiliki gradien temperatur, interaksi partikel gas dengan permukaan material regenerator menghasilkan proses thermodinamika yang serupa dengan siklus Stirling. Namun demikian, TATWE yang secara real mampu membangkitkan acoustic power pertama kali dibangun oleh Yazaki dkk. (1998). Namun efisiensinya masih sangat rendah karena kerugian viskos dalam regenerator masih sangat besar.

Satu dekade kemudian, Backhaus dan Swift (1999) memperkenalkan TATWE varian baru dengan efisiensi thermal mesin meningkat singnifikan. Backhaus dan Swift (2000) menjelaskan bahwa mesin ini bekerja berdasarkan Teori Akustik Linier, didetailkan oleh Swift (2001). Sebagian besar mesin termoakustik dewasa ini dikembangkan dari konfigurasi dasar Yazaki dkk. (1998) serta Backhaus dan Swift (1999) berlandaskan Teori Akustik Linier Swift (2001).

Mesin Wu dkk. (2012) berkonfigurasi identik dengan mesin Backhaus dan Swift (1999), sourcenya bertemperatur relatif sangat tinggi untuk ukuran teknologi pembangkitan yang murah, yaitu $650^{\circ} \mathrm{C}$. Tekanan kerja rata-rata juga relatif besar yaitu 3,5 MPa. Efisiensi termal mesin berkisar $30 \%$. Mesin ini hasil pengembangan selama 6 tahun dari model awal yang berefisiensi thermal $7 \%$.

Menimbang dari aspek penerapan di pedesaan, maka sebagai langkah awal dalam penelitian ini akan diterapkan mesin konfigurasi Yazaki dkk. (1998) dengan mereferensi Yu dkk. (2012), sebagai tahap permulaan pembangunan model simulasi untuk proses pengembangan di masa mendatang. Penerapan model mesin ini secara aktual merupakan tantangan tersendiri, karena pembuatannya dilakukan tidak hanya berdasarkan pertimbangan efisiensi termal yang tinggi tetapi juga terkait dengan kondisi operasi dan kontinuitas ketersediaan sumber kalor yang digunakan sebagai driving force mesin ini. Dengan demikian, efisiensi termal umumnya dikompromikan dengan faktor desain dan kondisi operasi, THATEA (2012). Salah satu penerapan teknologi termoakustik untuk sumber energi baru terbarukan yang telah berhasil dibangun setelah sekitar 8 tahun dikembangkan dengan simulasi model awal adalah mesin TATWE dari Wu dkk. (2012), dimana mesin ini bersumber kalor energi matahari.

Berdasarkan studi literatur, mesin yang didesain dengan $\mathrm{HHX}$ dan $\mathrm{CHX}$ berkemampuan khusus yang dapat memakai dua sumber kalor secara bersamaan yaitu dari pembakaran biomassa dan bahan bakar fosil belum ada. Namun demikian, mesin termoakustik experimental dengan berbagai varian yang bersumber kalor dari aliran gas panas sudah banyak dibangun. Diantara model yang telah berhasil dikembangkan adalah desain mesin loop tunggal dari Hao dkk. (2018). Ekstraksi energi mekanik dari energi akustik suatu mesin termoakustik dapat dilanjutkan hingga terkonversi menjadi listrik. Konversi daya mekanik menjadi daya listrik dapat dilkukan dengan menggunakan generator listrik linier. Termutakhir, Timmer dkk. (2018) telah membangun dan menjelaskan teknik konversi daya akustik hingga menjadi daya listrik seperti dimaksud.

Dalam tulisan ini dilakukan simulasi model untuk aplikasi secara real yang berbeda dengan simulasi lain. Simulasi dilakukan dalam dua tahapan umum. Diawal dibangun satu model mesin termoakustik loop tunggal yang mampu membangkitkan daya akustik dengan masukan kalor secara 
khusus dari gas panas hasil pembakaran terbuka biomasa yang banyak terdapat di pedesaan. Diteruskan dengan simulasi lanjutan model awal mesin sehingga terbangun beberapa model mesin lain. Sebagai hasilnya, karakteristik pembangkitan daya akustik semua model diketahui yaitu pada beberapa kombinasi dua parameter geometri regenerator, luas penampang radial dan panjang regenerator.

Keberadaan aliran energi akustik di lokasi manapun suatu mesin termoakustik dapat dinyatakan dengan suatu persamaan yang mengandung variabel kompleks. Persamaan umum energi akustik yang mengalir ke kanan pada rentang $d x$ akan memiliki daya akustik (acoustic power) $d E_{a}$ sesuai persamaan Swift (2001) di persamaan 1,

$$
\frac{d \dot{E}_{a}}{d x}=-\frac{r_{v}}{2}\left|U_{1}\right|^{2}-\frac{1}{2 r_{\kappa}}\left|p_{1}\right|^{2}+\frac{1}{2} \operatorname{Re}\left[g U_{1} \tilde{p}_{1}\right]
$$

Persamaan 2 adalah pernyataan umum variabel kompleks $\xi_{1}$ untuk menyatakan osilasi sinusoidal dari dua variabel, (a) laju aliran volume $U_{1}$ dan (b) tekanan $p_{1}$ yang ada pada persamaan 1 . Variabel $\xi_{1}$ tersebut mempunyai magnitudo $\left|\xi_{1}\right|$ dan sudut fasa $\theta$.

$$
\xi_{1}=\operatorname{Re}\left[\xi_{1} e^{i \omega t}\right]
$$

Dalam persamaan 1 ditunjukkan ada tiga komponen yang berkontribusi langsung dalam kejadian pembangkitan daya suatu mesin termoakustik. Suku pertama, yaitu suku disipasi viskos yang mengandung parameter viscous penetration depth $r_{v}$. Suku ini selalu terkait dengan keberadaan magnitude laju aliran volume $\left|U_{1}\right|$. Suku kedua, yaitu suku disipasi relaksasi thermal dengan parameter thermal penetration depth $r_{k}$. Suku ini selalu terkait dengan keberadaan magnitude driving force gelombang tekanan $\left|p_{1}\right|$. Dua komponen ini selalu bertanda negatif yang mengindikasikan bahwa daya akan selalu diperlemah dibawah pengaruh keduanya. Jika parameter desain yang diterapkan pada simulasi mesin termoakustik dirubah namun justru memperbesar dua suku ini maka evaluasi diperlukan. Suku ketiga, yaitu suku terakhir menjadi satu-satunya faktor pada mesin termoakustik yang dapat direkayasa sebagai parameter desain agar mesin termoakustik mampu membangkitkan daya. Walaupun tanda di depan suku ini adalah positif, namun nilai numerik suku ini dapat menjadi positif atau negatif tergantung kesetimbangan setting seluruh parameter mesin. Dalam suku ini, daya akustik dapat dibangkitkan atau malah terdisipasi tergantung dari parameter $g$. Karena sifatnya tersebut, suku ketiga sering diistilahkan sebagai sumber daya akustik, acoustic source. Dengan demikian, suku ketiga ini hanya mungkin ada dan terjadi di dalam regenerator.

Dengan demikian, langkah awal setiap proses desain mesin termoakustik adalah pengkondisian suku ketiga agar berfungsi sebagai acoustic source yaitu membangkitkan daya sebesar-besarnya, namun pada saat bersamaan juga mampu menekan pengaruh dua suku disipasi bertanda negatif menjadi sekecil-kecilnya.

Suku acoustic source dapat ditulis lebih detail dengan mengandaikan bahwa thermal penetration depth berkontribusi signifikan, seperti pada persamaan 3.

$$
\frac{1}{2} \operatorname{Re}\left[g U_{1} \tilde{p}_{1}\right]=\frac{1}{2} \frac{1}{T_{m}} \frac{d T_{m}}{d x} \operatorname{Re}\left[\tilde{p}_{1} U_{1}\right] \operatorname{Re}\left[f_{\kappa}\right]+\frac{1}{2} \frac{1}{T_{m}} \frac{d T_{m}}{d x} \operatorname{Im}\left[\tilde{p}_{1} U_{1}\right] \operatorname{Im}\left[-f_{\kappa}\right]
$$

Suku kedua persamaan 3 adalah suku yang merepresentasikan komponen standing-wave dari gelombang akustik yang mengalir dalam loop mesin. Karena itu fokus rekayasa dalam simulasi ini diarahkan untuk memaksimalkan suku pertama. Dengan mencermati suku pertama persamaan 3 , yaitu suku yang mengandung komponen travelling-wave, diketahui ada tiga hal berpengaruh pada pembangkitan daya di acoustic source, yaitu (a) $\left(d T_{m} / d x\right)$, (b) $\operatorname{Re}\left[\tilde{p}_{1} U_{1}\right]$, dan (c) $\operatorname{Re}\left[f_{\kappa}\right]$.

Faktor (a) adalah gradien temperatur, yang secara aktual dimungkinkan dengan adanya $\mathrm{HHX}$ dan $\mathrm{CHX}$ di kedua sisi REG. Dalam penelitian ini, beda temperatur disetting konstan. Berikutnya faktor (b) adalah daya akustik umpan yang harus ada dan mengalir di dalam mesin. Di dalam skema mesin pada gambar 1, faktor ini diistilahkan sebagai daya akustik umpan $\left(E_{a i}\right)$. Terakhir, faktor (c) mengandung berbagai variabel regenerator termasuk diantaranya beberapa variabel geometri. Diantara variabel geometri regenerator yang berpengaruh memperbesar nilai $\operatorname{Re}\left[f_{K}\right]$ adalah panjang 
regenerator dan luas penampangnya. Namun demikian, penambahan panjang dan memperbesar luas penampang regenerator tidak secara pasti akan memperbesar keluaran daya akustik mesin karena kerugian disipasi viskos yang mesin seperti ditunjukkan persamaan 1 juga akan membesar.

\section{METODE PENELITIAN}

Sebuah model TATWE dibangun secara simulasi menggunakan software open source DELTAEC. Dipakai DELTA-EC Versi 6.2 dari Ward dkk. (2008). Konstruksi model mesin seperti pada gambar 1. Mesin terdiri dari satu Cold Heat Exchanger, alat penukar kalor sisi temperatur rendah, CHX, satu regenerator (REG), satu Hot Heat Exchanger, yaitu alat penukar kalor sisi temperatur tinggi, HHX, dan sebuah saluran penghubung antara sisi keluar HHX dengan sisi masuk $\mathrm{CHX}$ yang disebut DUCT. Komponen tersebut disusun berurutan dalam arah aliran daya akustik seperti pada gambar 1 . Semua segmen mesin terhubung rapat dan tanpa celah. DUCT menghubungkan sisi keluar HHX sampai sisi masuk $\mathrm{CHX}$ sehingga komponen mesin secara keseluruhan membentuk satu loop tunggal yang kontinu.
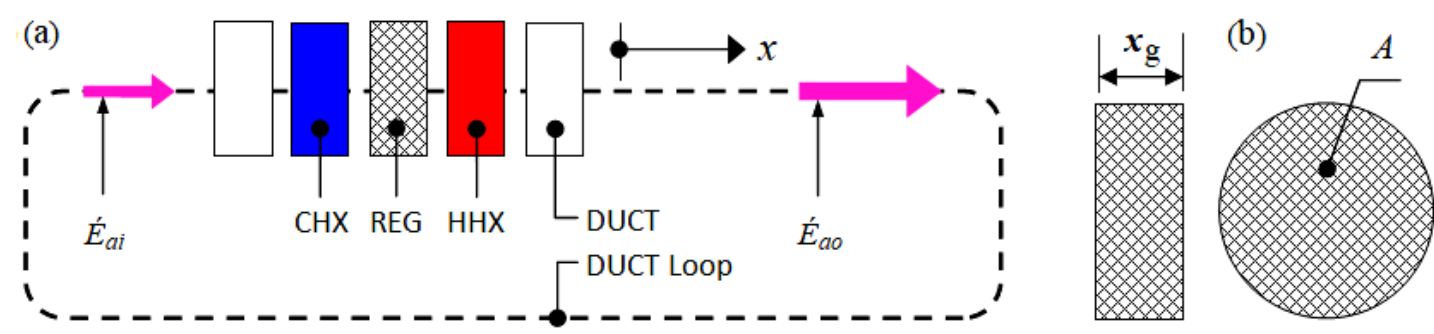

Gambar 1. (a) Model simulasi mesin TATWE, dan (b) simbol dimensi regenerator

$\mathrm{CHX}$ dan HHX dimodelkan dalam simulasi sebagai alat penukar kalor jenis tube and shell, dengan tube berbentuk pipa lurus sekali lintas. Luas area sisi dalam penampang pipa tube secara keseluruhan berbanding luas penampang $\mathrm{CHX}$ atau $\mathrm{HHX}$ disebut sebagai porositas volume alat penukar kalor. Luas penampang radial CHX, REG, HHX, dan DUCT dalam simulasi ini disetting sama sebesar $100 \mathrm{~mm}^{2}$. Sisi shell HHX dimodelkan menerima suplai kalor dari gas pembakaran biomassa secara langsung, dengan sisi masuk dan sisi keluar gas terpapar langsung ke lingkungan. Selain itu, model shell HHX tersebut juga dapat menerima suplai kalor dari gas hasil pembakaran berbagai jenis bahan bakar fosil. Bahan pipa $\mathrm{CHX}$ dan HHX adalah stainless steel. Regenerator dimodelkan terbuat dari woven wire mesh berdiameter hidrolik 66 mikron, dengan porositas $72 \%$. Ukuran mesh regenerator dalam penomoran komersial 140, dengan konversi menjadi diameter hidrolik pada tabel 1. Material regenerator dan DUCT dimodelkan terbuat dari material baja tahan karat juga.

Tabel 1. Parameter konstan mesin hasil simulasi DELTA-EC

\begin{tabular}{lccc}
\hline \multicolumn{1}{c}{ Nama parameter } & Simbol & Satuan & Nilai \\
\hline Tekanan rata-rata & $P_{m}$ & atm & 1 \\
Temperatur CHX & $T_{s c}$ & $\mathrm{~K}$ & 300 \\
Temperatur HHX & $T_{s h}$ & $\mathrm{~K}$ & 643 \\
Kalor suplai HHX & $Q_{h}$ & $\mathrm{~W}$ & 847 \\
Porositas volume CHX & - & - & 0,50 \\
Porositas volume HHX & - & - & 0,50 \\
Porositas volume REG & $\phi$ & - & 0,72 \\
Diameter hidrolik REG & \multicolumn{3}{c}{ mikron } \\
Fluida kerja mesin & $r_{h}$ & 66 \\
\hline
\end{tabular}

Daya akustik $E_{a i}$, yaitu $\operatorname{Re}\left[\tilde{p}_{1} U_{1}\right]$ pada persamaan 3, diumpankan masuk ke CHX kemudian daya akustik diperbesar didalam REG sehingga menjadi $E_{\text {ao }}$ pada gambar 1 , atau dalam arti yang sama $\left(d \dot{E}_{a} / d x\right)$ pada persamaan 1. Pemodelan didasarkan pada teori akustik linear satu dimensi arah $x$, yaitu searah amplifikasi daya akustik. Area regenerator $A$ adalah luas penampang radial yang diasumsikan konstan sepanjang $x$. Panjang regenerator adalah $x_{g}$, dari pernyataan diferensial $d x$. Nilai $\dot{E}_{a i}$ dan $\dot{E}_{a o}$ diketahui dari simulasi. 
Nilai parameter konstan tabel 1 adalah nilai eksak hasil simulasi, yaitu dari simulasi awal dalam penentuan parameter model yang sesuai kondisi operasional real. Simulasi lanjutan dilakukan sehingga diketahui pengaruh luas area penampang $A$ dan panjang regenerator $x_{\mathrm{g}}$. Temperatur $\mathrm{HHX}$ dalam tabel 1 masih berada dalam rentang temperatur pembakaran biomassa hingga $700^{\circ} \mathrm{C}$, Siregar dkk. (2017). Kondisi lingkungan diandaikan bertemperatur tetap yang sama dengan Temperatur CHX, yaitu $300 \mathrm{~K}$.

Dengan demikian pembangkitan daya akustik $E_{a}$ oleh regenerator menjadi,

$$
\dot{E}_{a}=\dot{E}_{a o}-\dot{E}_{a i}
$$

Sedangkan efisiensi konversi energi kalor menjadi energi akustik $\eta$ adalah,

$\eta=\left(\dot{E}_{a} / Q_{h}\right) 100 \%$

Simulasi ini menggunakan metode integrasi numerik Range-Kutta empat sub-segmen, dimana keluaran suatu segmen dipakai sebagai masukan untuk segmen berikutnya dengan kondisi batas berbeda tergantung kondisi tiap segmen. Diantara kondisi batas adalah tekanan rata-rata dalam mesin $p_{m}$, geometri tiap segmen, properti termodinamika gas fluida kerja mesin, dan properti material mesin.

\section{HASIL DAN PEMBAHASAN}

Dari simulasi tahap awal diperoleh sebuah model mesin dengan suatu parameter desain tertentu. Selain $A$ dan $x_{g}$, ada dua parameter geometri regenerator lain yang juga penting. Dua parameter tersebut adalah $r_{h}$ dan $\phi$ yang selalu dianggap konstan dengan nilai numerik masingmasing pada tabel 1 . Selain parameter pada tabel 1, diperoleh juga hasil simulasi yang mengarah pada suatu model yang stabil dengan keluaran realistis untuk luas penampang tertentu dari HHX dan $\mathrm{CHX}$, yaitu $A_{H}$ dan $A_{C}$. Secara kriteria desain, luas penampang regenerator $A$ dibuat sama dengan $A_{H}$ dan $A_{C}$. Kondisi tersebut tercapai pada hasil simulasi konvergen dengan $A=100 \mathrm{~mm}^{2}$. Simulasi lanjutan pada $A=100 \mathrm{~mm}^{2}$ yang konstan menunjukkan karakteristik keluaran daya akustik $E_{a}$ dan efisiensi $\eta$ mesin pada berbagai panjang regenerator $x_{g}$ ditunjukkan dalam gambar 2 dan gambar 3 , yaitu sebaran data dan trendline yang dilambangkan "A100". Di gambar 2 dan gambar 3 tersebut, simbol A80 dan A120 berturut-turut mewakili juga variabel luas regenerator $A=80 \mathrm{~mm}^{2}$ dan $A=120$ $\mathrm{mm}^{2}$.

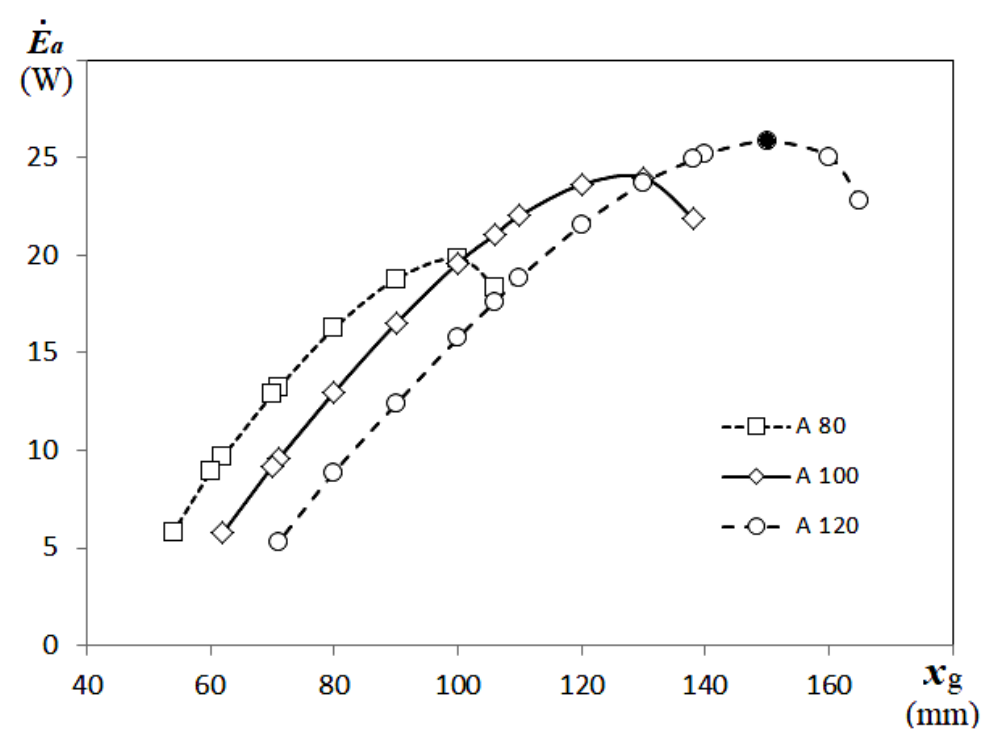

Gambar 2. Daya akustik semua model TATWE pada berbagai panjang regenerator

Data A100 gambar 2 menunjukkan bahwa panjang regenerator sangat berpengaruh terhadap keluaran daya akustik mesin TATWE loop tunggal yang menjadi model dalam tulisan ini. Semakin 
panjang regenerator, semakin besar daya akustik yang dihasilkan. Namun demikian ada batasan panjang maksimum dari regenerator sebelum mesin tidak dapat bekerja, atau secara simulasi, keluaran variabel fisis mesin menjadi tidak realistis. Mesin hanya dapat bekerja sampai pada $x_{g}$ maksimum $138 \mathrm{~mm}$, dengan keluaran daya pada kondisi tersebut 21,894 W. Namun demikian, daya akustik tertinggi tidak terjadi pada nilai maksimum ini. Daya akustik tertinggi $\dot{E}_{a}=23,994 \mathrm{~W}$ dihasilkan pada panjang regenerator $x_{g}=130 \mathrm{~mm}$, yang lebih pendek $8 \mathrm{~mm}$ dari panjang maksimum. Mesin tetap dapat bekerja dengan regenerator yang lebih pendek, hingga panjang minimum $62 \mathrm{~mm}$, dengan daya akustik terendah yaitu $5,766 \mathrm{~W}$. Sama dengan sebelumnya, simulasi dengan regenerator yang lebih pendek dari panjang minimum menunjukkan kondisi variabel operasi mesin yang tidak rasional. Selain itu, simulasi perhitungan daya akustik diluar span panjang minimum sampai maksimum menjadi tidak akurat. Persentase toleransi kesalahan nilai numerik diluar span bahkan mendekati 5\%, sangat jauh dari tolerasi normal simulasi DELTA-EC yang diijinkan tidak lebih dari $0,01 \%$, terutama di lokasi fisik sambungan loop. Di dalam model, lokasinya di pertemuan ujung DUCT keluar HHX dengan ujung DUCT masuk CHX.

Hal lain yang dapat diamati dari kurva A100 adalah perbedaan panjang span dari dua segmen kurva, yaitu segmen kurva dari $x_{g}$ minimum hingga $x_{g}$ pembuat $\dot{E}_{a}$ maksimum yang lebih panjang sekitar 8 kali dibanding segmen kurva antara $x_{g}$ pembuat $E_{a}$ maksimum hingga $x_{g}$ maksimum. Kondisi ini menggambarkan bahwa suatu panjang aktual regenerator yang dipilih akan lebih andal dalam merespon perubahan masukan, seperti suplai kalor, bila berada di bawah nilai $x_{g}$ pembuat $\dot{E}_{a}$ maksimum.

Investigasi lain dilakukan untuk mengetahui efek luas area penampang regenerator $A$ terhadap keluaran daya akustik $\dot{E}_{a}$ model mesin. Simulasi dilakukan pada berbagai panjang regenerator $x_{g}$ dengan luas $A$ yang lebih kecil $20 \%$ pada $A=80 \mathrm{~mm}^{2}$ (A80), dan $A$ lebih besar $20 \%$ atau $A=120$ $\mathrm{mm}^{2}$ (A120). Bentuk kurva A80 dan A120 serupa dengan A100. Pada A80, daya akustik yang dihasilkan lebih besar pada suatu panjang regenerator. Sebagai contoh, pada panjang regenerator 80 $\mathrm{mm}$, daya akustik pada generator dengan luas $80 \mathrm{~mm}^{2}$ adalah 16,266 W. Dayanya lebih tinggi sekitar $25 \%$ dibandingkan dengan yang ditunjukkan kurva A100 pada $x_{g}$ yang sama. Namun demikian, nilai maksimum $E_{a}$ pada $A 80$ sebesar $19,898 \mathrm{~W}$ yang terjadi pada $x_{g}=100 \mathrm{~mm}$ lebih rendah $20 \%$ dibandingkan $E_{a}$ maksimum $A 100$ yang terjadi pada $x_{g}=130 \mathrm{~mm}$. Serupa dengan A100, setelah tercapai $E_{a}$ maksimum pada $A 80$, hanya sedikit penambahan panjang regenerator yang dapat diberikan. Dapat dilihat pula bahwa segmen kurva antara $x_{g}$ minimum hingga $x_{g}$ pembuat $\dot{E}_{a}$ maksimum, menjadi lebih pendek.

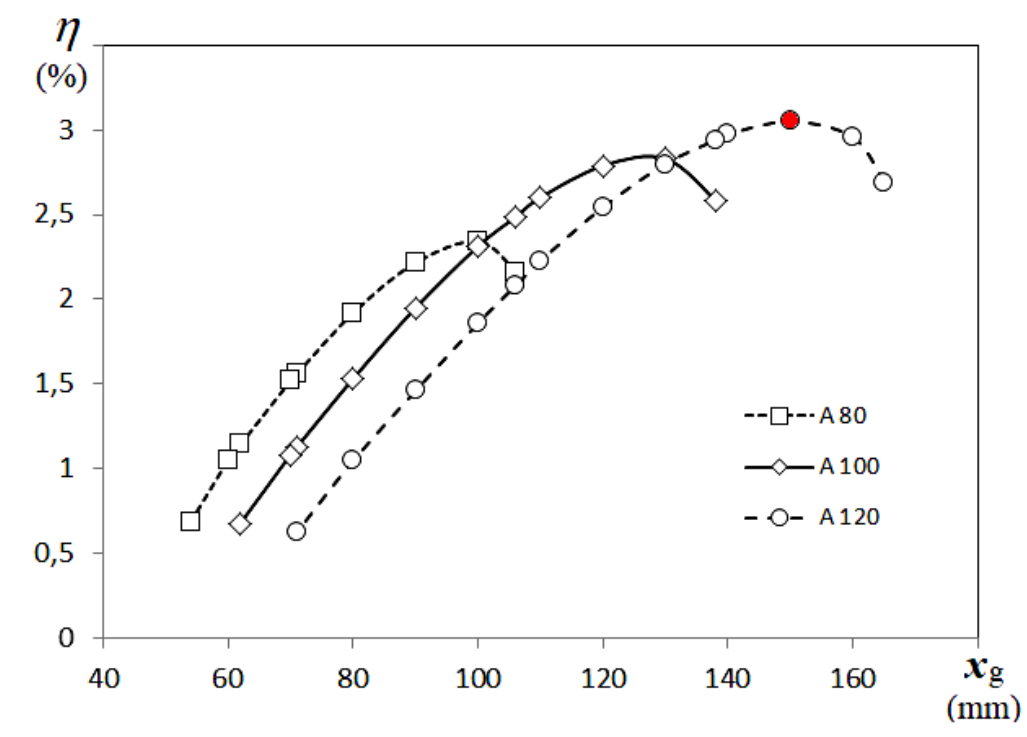

Gambar 3. Efisiensi konversi energi kalor model TATWE pada berbagai panjang regenerator

Penambahan area regenerator menjadi A120 menyebabkan efek terbalik dibanding A80. Segmen kurva antara $x_{g}$ minimum hingga $x_{g}$ pembuat $\dot{E}_{a}$ maksimum, menjadi lebih panjang. Hal ini lebih baik untuk pengaturan operasional mesin. Keluaran daya akustik $E_{a}$ menjadi lebih besar, dan mencapai maksimum $\dot{E}_{a \cdot \max }=25,848 \mathrm{~W}$ pada panjang regenerator $x_{\text {g.max }}=130 \mathrm{~mm}$. Keluaran $\dot{E}_{a \cdot \max }$ 
yang ditandai ikon solid hitam menjadi model mesin dengan prestasi terbaik, yaitu dibandingkan dengan keluaran $\dot{E}_{a}$ tiap 33 model mesin yang sudah dibangun dan diuji simulasi. Model mesin terbaik tersebut disebut $T A T W E_{\text {Max }}$. Prestasi tiap model mesin pada gambar 2 diwakili oleh tiap satu titik data.

Karakteristik efisiensi mesin dapat dilihat pada gambar 3. Sebaran data dan trend bentuk kurva gambar 3 identik dengan gambar 2. Perbedaan area regenerator dari A80, A100, dan A120 menyebabkan perbedaan efisiensi maksimum mesin, yang berturut-turut $2,344 \%, 2,832 \%$, dan $3,051 \%$. Efisiensi maksimum $\eta_{\max }=3,051 \%$ terjadi pada keluaran daya akustik maksimum $E_{\text {a.max }}=$ $25,848 \mathrm{~W}$, yaitu pada simulasi dengan kombinasi dua parameter geometri regenerator yang sama $x_{g \cdot \max }=130 \mathrm{~mm}$ dengan $A=120 \mathrm{~mm}^{2}$. Keluaran $\eta_{\max }$ yang ditandai ikon solid merah, menjadi efisiensi terbaik mesin, hasil ini juga dibandingkan dengan 32 model mesin lainnya.

Gambar 2 dan gambar 3 menunjukkan juga perbandingan dari karakteristik model mesin hasil simulasi. Semakin tinggi daya akustik keluaran mesin, maka secara rasional akan memberikan efisiensi kerja mesin yang lebih baik. Demikian pula sebaliknya. Namun perlu disampaikan bahwa perbandingan dalam tulisan ini dilihat dari kondisi kalor masukan untuk mesin yang konstan $Q_{h}$, yang dari tabel 1 diketahui nilainya sebesar $847 \mathrm{~W}$. Selain itu, temperatur HHX dijaga konstan sebesar $T_{s h}$ $=643 \mathrm{~K}$ untuk menjamin beda temperatur yang konstan. Namun, beda temperatur konstan belum tentu menghasilkan $\left(d T_{m} / d x\right)$ yang konstan juga, dikarenakan $d x$ divariasikan.

Karakteristik hubungan keluaran daya akustik dengan panjang regenerator dari mesin TATWE Napolitano dkk. (2017) $\left(T A T W E_{\mathrm{N}}\right)$ menunjukkan pola kurva sebaran data yang sangat serupa dengan pola hasil simulasi pada gambar 2. Segmen kurva antara $x_{g}$ minimum hingga $x_{g}$ pembuat $E_{a}$ maksimum menunjukkan pola yang sama, demikian pula pada segmen kurva antara $x_{g}$ pembuat $\dot{E}_{a}$ maksimum hingga $x_{g}$ maksimum. Dengan panjang regenerator $80 \mathrm{~mm}$, mesin tersebut menghasilkan daya yang jauh lebih tinggi dibandingkan model TATWE $E_{\text {axa }}$, sekitar 140 kali lipat. Namun demikian, daya akustik yang besar tersebut diperoleh dengan setting mesin berbeda. Pertama, mesin TATWE adalah jenis torus dengan desain lebih kompleks. Sedangkan mesin TATWE $E_{\operatorname{Max}}$ adalah jenis loop tunggal dengan komponen yang lebih sederhana. Kedua, kalor suplai $\mathrm{HHX} T A T W E_{\mathrm{N}}$ adalah $3700 \mathrm{~W}$, sekitar 4,5 kali dari kalor suplai yang diberikan pada mesin $T A T W E_{\text {Max }}$. Ketiga, temperatur $\mathrm{HHX}$ $T A T W E_{N}$ juga berbeda, lebih tinggi $148^{\circ} \mathrm{C}$. Desain mesin yang sama dengan model dalam tulisan ini dibangun oleh Yu dkk. (2012). Jenis mesin adalah loop tunggal. Efisiensi konversi energi kalor menjadi energi akustik mesin Yu dkk. (2012) masih dibawah 2\%, dengan keluaran daya akustik tertinggi tidak lebih dari $50 \mathrm{~W}$. Masukan kalor mesin disetting konstan juga. Tekanan operasi rata-rata mesin Yu dkk. (2012) adalah $1 \mathrm{~atm}$, sama dengan tekanan rata-rata yang diaplikasikan pada model simulasi dalam tulisan ini. Panjang regenerator adalah $33 \mathrm{~mm}$, dengan penampang lingkaran berdiameter $110 \mathrm{~mm}$. Dari perbandingan dengan dua referensi tersebut menunjukkan bahwa ada banyak faktor yang menentukan prestasi suatu mesin termoakustik, tergantung dari pengaturan parameter desain mesin dan parameter operasionalnya. Terakhir, dari ketiga kurva A80, A100, dan A120, baik pada gambar 2 maupun gambar 3, dapat dilihat tiga hal. Pertama mesin dapat bekerja hanya pada suatu kondisi dimana amplifikasi daya akustik minimum sekitar $5 \mathrm{~W}$, pada efisiensi sekitar $0,5 \%$. Pada daerah dibawah itu, simulasi menunjukkan dimensi regenerator yang dipakai belum dapat menjalankan fungsinya membangkitkan energi akustik walaupun telah diberikan beda temperatur relatif besar. Kedua, dua parameter geometri regenerator, yaitu $A$ dan $x_{g}$, saling mempengaruhi. Hal ini berarti dua faktor geometri tersebut sama-sama signifikan dalam desain mesin termoakustik. Regenerator dengan area lebih kecil akan memberikan keluaran daya dan efisiensi lebih besar, namun pada daerah operasi yang lebih sempit. Kebalikannya, regenerator dengan area lebih besar efisiensi dan keluaran daya akustiknya lebih rendah, namun range operasi menjadi lebih luas, dan ini sangat diinginkan secara aplikasi dengan tujuan fleksibilitas operasional aktual mesin. Ketiga dan paling penting, regenerator yang lebih luas penampangnya memiliki kemampuan membangkitkan energi akustik lebih besar bila regenerator didesain dengan panjang yang tepat.

Berdasarkan kurva A80, A100, dan A120 gambar 2 dan gambar 3 dapat dilihat bahwa simulasi pada luas penampang dan panjang regenerator lain berkemungkinan memberikan daya dan efisiensi yang lebih tinggi, dengan masukan kalor dan temperatur HHX yang sama. Selain itu, simulasi dapat dilakukan untuk mencari pengaruh faktor geometri lain untuk meningkatkan efisiensi mesin. Efektifitas $\mathrm{HHX}$ dan $\mathrm{CHX}$ juga menjadi isu lain, sebab temperatur $\mathrm{HHX}$ yang lebih tinggi masih mungkin diperoleh bila pengaturan desainnya dapat meningkatkan laju perpindahan kalor tanpa memperbesar suplai kalor. 


\section{KESIMPULAN}

Regenerator yang lebih luas penampangnya memiliki kemampuan membangkitkan energi akustik lebih besar pada suatu panjang regenerator yang sama, namun kemampuan regenerator semakin rendah dalam amplifikasi daya akustik. Simulasi telah menghasilkan satu model terbaik dari 33 model mesin yang dibangun. Model mesin terbaik tersebut mampu membangkitkan energi akustik tertinggi sebesar 25,848 W, dengan efisiensi konversi dari kalor menjadi daya akustik sebesar 3,05\%. Model tersebut menggunakan regenerator dengan luas penampang $120 \mathrm{~mm}^{2}$ dan panjang $150 \mathrm{~mm}$.

\section{UCAPAN TERIMAKASIH}

Penulis mengucapkan terimakasih kepada Kalid Abdoulla atas beberapa saran berharga dalam penentuan rute debugging DELTA-EC yang efektif.

\section{DAFTAR NOTASI}

A : Luas penampang radial regenerator $\left(\mathrm{mm}^{2}\right)$

$\dot{E}_{a} \quad$ : Amplifikasi daya akustik oleh regenerator (W)

$f_{k} \quad$ : Fungsi karakteristik termoviskos spasial rata-rata regenerator

$g \quad$ : Fungsi kompleks pembangkitan daya akustik regenerator

Im[] : Bagian imaginer fungsi kompleks dalam tanda kurung []

$P_{m} \quad$ : Tekanan kerja rata-rata mesin (atm)

$p_{1} \quad$ : Amplitudo gelombang tekanan dalam pernyataan kompleks (atm)

$Q_{h} \quad$ : Kalor yang disuplai ke dalam $\mathrm{HHX}(\mathrm{W})$

$\mathrm{Re}[\mathrm{S} \quad$ : Bagian real fungsi kompleks dalam tanda kurung []

$r_{h} \quad:$ Diameter hidrolik regenerator $(\mathrm{mm})$

$r_{v} \quad$ : Viscous penetration depth $(\mathrm{mm})$

$r_{k} \quad:$ Thermal penetration depth $(\mathrm{mm})$

$T_{m} \quad$ : Temperatur rata-rata dalam mesin (K)

$T_{\text {sh }} \quad$ : Temperatur dinding dalam pipa $\mathrm{HHX}(\mathrm{K})$

$T_{s c} \quad$ : Temperatur dinding dalam pipa $\mathrm{CHX}(\mathrm{K})$

$U_{1} \quad$ : Amplitudo laju aliran volume dalam pernyataan kompleks $\left(\mathrm{m}^{3} / \mathrm{s}\right)$

$x_{g} \quad$ : Panjang regenerator $(\mathrm{mm})$

$\eta \quad$ : Efisiensi konversi kalor menjadi daya akustik (\%)

\section{DAFTAR PUSTAKA}

Backhaus S., Swift G.W., 1999, A thermoacoustic Stirling heat engine, Nature, 399, 335-338

Backhaus S., Swift G.W., 2000, A thermoacoustic Stirling heat engine: Detailed Study, JASA, 107(6), 3148-3166

Ceperley P.H., 1979, A pistonless Stirling engine - The traveling wave heat engine, JASA, 66(5)

Siregar K., Alamsyah R., Ichwana, Sholihati, Tou S.B., 2017, Rancang bangun mesin pembangkit listrik tenaga biomassa pada daerah terisolasi, Prosiding Seminar Nasional FKPT-TPI 2017, Kendari, 150-162

Hao H., Scalo C., 2018, Standing-wave and traveling-wave thermoacoustics in solid media, JASA, 144

Napolitano M., Dragonetti R., Romano R., 2017, A method to optimize the regenerator parameters of a thermoacoustic engine, Energy Procedia, 126(201709), 525-532

Swift G.W., 2001, Thermoacoustics: A unifying perspective for some engines and refrigerators, Fifth Draft, Los Alamos USA

Timmer M.A.G., Meer T.H., Blok K.D., 2018, Review on the conversion of thermoacoustic power into electricity, JASA, 143(2)

THATEA, 2012, Thermoacoustic Technology for Energy Applications, ECN Netherlands

Ward B., Clark J., Swift G.W., 2008, Design Environment for Low-Amplitude Thermoacoustic Energy Conversion (DELTA-EC) Version 6.2, Los Alamos USA

Wu Z., Dai W., Man M., Luo E., 2012, A solar powered traveling wave thrmoacoustic electricity generator, Solar Energy, 86(9), 2376-2382

Yazaki T., Iwata A., Maekawa T., Tominaga A., 1998, Traveling wave thermoacoustic engine in a looped tube, Physical Review Letters, 81(15), 3128-3131

Yudiartono, Anindhita, Sugiyono A., Wahid L.M.A., Adiarso, 2018, Outlook Energi Indonesia 2018, BPPT Indonesia 
Yu Z., Jaworski A.J., Backhaus S., 2010, A low-cost electricity generator for rural areas using a travelling-wave looped-tube thermoacoustic engine, Proceedings IME Part-A Power and Energy 2010, 224-787 